\title{
DIMENSI METRIK DAN DIAMETER DARI GRAF ULAT
}

$$
\mathbf{C}_{\mathbf{m}, \mathbf{n}}
$$

\author{
Restu Ria Wantika \\ Pendidikan Matematika, Fakultas Keguruan dan Ilmu Pendidikan, Universitas PGRI Adi \\ Buana Surabaya \\ Resturiawantika89@gmail.com
}

\begin{abstract}
Graf is a pair $(V, E)$ where $\mathrm{V}$ set of vertices is not empty and $\mathrm{E}$ set side. Let $\mathrm{u}$ and $\mathrm{v}$ are the vertices in a connected graph $\mathrm{G}$, then the distance $\mathrm{d}(\mathrm{u}, \mathrm{v})$ is the length of the shortest path between $u$ and $v$ in $G$. The diameter of graph $G$ is the maximum distance of $\mathrm{d}(\mathrm{u}, \mathrm{v})$. For the set of ordered $W=$ $\left\{w_{1}, w_{2}, w_{3}, w_{4}, \ldots \ldots, w_{k}\right\}$ of vertices in a connected graph $\mathrm{G}$ and vertex $v \in V(G)$, the representation of $\mathrm{v}$ to $\mathrm{W}$ is $r(v \mid W)=$ $\left(d\left(v, w_{1}\right), d\left(v, w_{2}\right), d\left(v, w_{3}\right), \ldots \ldots \ldots, d\left(v, w_{k}\right)\right)$. If $\mathrm{r}(\mathrm{v} \mid \mathrm{W})$ for each node $\mathrm{v} \in \mathrm{V}(\mathrm{G})$ are different, then $\mathrm{W}$ is called the set of variants from $\mathrm{G}$ and the minimum cardinality of the set differentiator is referred to as the metric dimensions. Based on the characteristics of the vertices and sides of the graph have many types of them are caterpillars and graph graph fireworks, which both have in common at the center of the graph shaped trajectory and earring starshaped graph. In this paper will prove that Graf caterpillar $\left(C_{m, n}\right)$ with $m \geq$ $1, n \geq 2$ has diameter $m+1$ and metric dimensions $m(n-1)$.
\end{abstract} Keywords: dimensional graph, graph diameter, star graph, graph caterpillar ..

\section{PENDAHULUAN}

Graf merupakan pasangan $(V, E)$ dimana $V$ himpunan simpul tak kosong dan $E$ himpunan sisi. Teori graf dapat digunakan untuk menyelesaikan berbagai jenis permasalahan, diantaranya adalah permasalahan tukang pos dan menentukan jarak terpendek. Diantara berbagai macam pokok bahasan dari teori graph, salah satu yang menarik adalah tentang dimensi metrik dari sebuah graf. Misalkan $u$ dan $v$ adalah simpul-simpul dalam graf terhubung $\mathrm{G}$, maka jarak $d(u, v)$ adalah panjang lintasan terpendek antara $u$ dan $v$ pada G. Untuk himpunan terurut $\quad W=$ $\left\{w_{1}, w_{2}, w_{3}, w_{4}, \ldots, w_{k}\right\}$ dari simpul-simpul dalam graf terhubung $\mathrm{G}$ dan simpul $v \in$ $V(G)$, representasi dari $v$ terhadap $W$ adalah

$r(v \mid W)$ $=\left(d\left(v, w_{1}\right), d\left(v, w_{2}\right), d\left(v, w_{3}\right), \ldots, d\left(v, w_{k}\right)\right)$

Jika $r(v \mid W)$ untuk setiap simpul $v \in$ $V(G)$ berbeda , maka $W$ disebut himpunan pembeda dari $G$. Himpunan pembeda 
dengan kardinalitas (banyak anggota) minimum disebut himpunan pembeda minimum atau basis. Kardinalitas dari basis tersebut dinamakan dimensi metrik dari $G$, yang dinotasikan $\operatorname{dim}(G)$. Diameter pada graf $\mathrm{G}$ adalah jarak maksimal dari $d(u, v)$.

Banyak penelitian tentang dimensi metrik salah satunya adalah Dimensi Metrik Graph Lobster (Pande Gede,dkk,2013). Dari analisis telah diperoleh dimensi metrik $L_{n}$ $(\mathrm{q}, \mathrm{r})$ adalah $\operatorname{dim} L_{n}(\mathrm{q}, \mathrm{r})=n(q-1)$ dengan $n$ $\geq 2, q \geq 2$ dan $r=1^{[1]}$. Sejauh ini dimensi metrik dan diameter pada graf ulat $C_{m, n}$ dan graf kembang api $F_{m, n}$ jarang ditemukan. Adapun jenis graf yang kita bahas pada paper ini antara lain Graf Bintang adalah graf dengan satu simpul pusat $k$ yang terhubung dengan $n$ simpul anting. Derajat dari simpul $k$ adalah $n$, sedangkan derajat simpul anting adalah 1. Graf bintang dinotasikan dengan $S_{1, n \text {. }}{ }^{[3]}$. Berikut adalah gambar dari graf bintang.

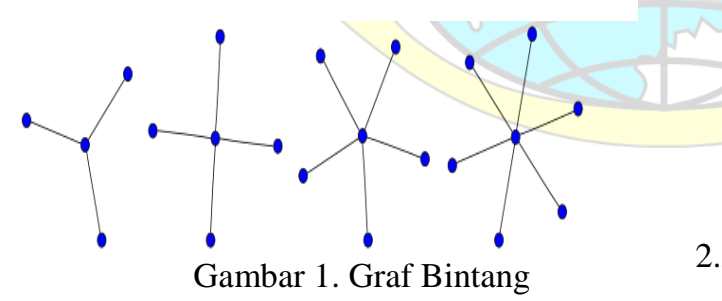

Graf Ulat $C_{m, n}$ adalah graf yang didapatkan dengan menghubungkan simpul pusat $a$ dari graf bintang secara berurutan. Lintasan yang menghubungkan simpul-simpul anting dari barisan graf bintang disebut backbone dari graf ulat. Dinotasikan dengan $C_{m, n}$ dengan $m$ adalah jumlah dari simpul backbone dan $n$ adalah jumlah dari simpul anting ${ }^{[4]}$. Berikut adalah gambar dari graf ulat

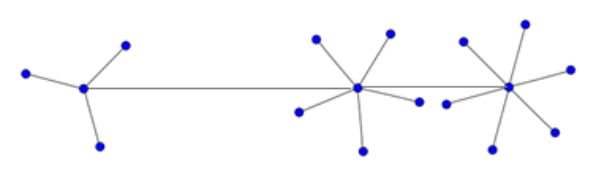

Gambar 2. Graf Ulat

Sedangkan Graf Kembang Api $\mathrm{F}_{\mathrm{m}, \mathrm{n}}$ adalah graf yang didapatkan dengan menghubungkan sisi dari $m$ simpul backbone ke simpul pusat dari $n$ graf bintang. Berikut gambar dari graf kembang api.

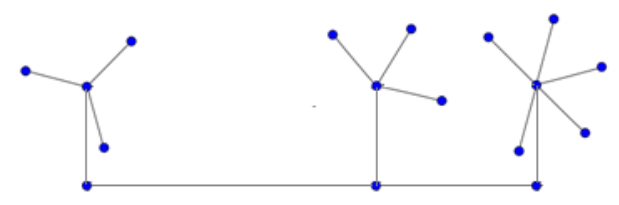

Gambar 2. Graf Kembang Api

\section{METODE PENELITIAN}

1. Studi literatur dan pemahaman konsep

Pada tahap ini akan dilakukan studi literature dari beberapa referensi buku, artikel,jurnal dari berbagai sumber mengenai penelitian dimensi metrik pada graf

2.Analisis
a. Melakukan observasi terhadap graf yang akan diteliti
b. Mencari resolving set kemudian mengkonstruksi himpunan pembeda sehingga didapat dimensi metrik 
batas bawah dan batas atasnya

c. Kemudian mencari diameternya menggunakan jarak

3.Evaluasi

Pada tahap ini melakukan evaluasi terhadap analisa yang telah dilakukan untuk mendapatkan dimensi metrik dan diameter pada graf ulat.

\section{PEMBAHASAN}

\section{Dimensi Metrik dan diameter dari} graf ulat dengan $m \geq 1, n \geq 2$

Untuk menentukan dimensi metrik dari graf ulat terlebih dahulu kita harus mengkonstruksi graf tersebut.

i. Mengkonstruksi Himpunan pembeda

$$
\begin{gathered}
\text { Graf } \mathbf{C}_{2,2} \\
W_{1}=\left\{a_{11}, a_{21}\right\} \\
r\left(a_{11} \mid W\right)=(0,3) \\
r\left(a_{12} \mid W\right)=(2,3) \\
r\left(a_{21} \mid W\right)=(3,0) \\
r\left(a_{22} \mid W\right)=(3,2) \\
r\left(a_{1} \mid W\right)=(1,2) \\
r\left(a_{2} \mid W\right)=(2,1) \\
W_{2}=\left\{a_{11}, a_{12}, a_{21}\right\} \\
r\left(a_{11} \mid W\right)=(0,2,3) \\
r\left(a_{12} \mid W\right)=(2,0,3) \\
r\left(a_{21} \mid W\right)=(3,3,0) \\
r\left(a_{22} \mid W\right)=(3,3,2) \\
r\left(a_{1} \mid W\right)=(1,1,2) \\
r\left(a_{2} \mid W\right)=(2,2,1)
\end{gathered}
$$

Terlihat $r(v \mid W)$ untuk setiap simpul $v \in$ $\mathrm{C}_{2,2}$ berbeda. Maka $\mathrm{W}_{1}$ dan $\mathrm{W}_{2}$ merupakan resolving set

\section{Graf $\mathbf{C}_{1,3}$}

$$
W_{1}=\left\{a_{11}, a_{12}\right\}
$$

$$
\begin{aligned}
& r\left(a_{11} \mid W\right)=(0,2) \\
& r\left(a_{12} \mid W\right)=(2,0) \\
& r\left(a_{13} \mid W\right)=(2,2) \\
& r\left(a_{1} \mid W\right)=(1,1) \\
& W_{2}=\left\{a_{11}, a_{12}, a_{13}\right\} \\
& r\left(a_{11} \mid W\right)=(0,2,2) \\
& r\left(a_{12} \mid W\right)=(2,0,2) \\
& r\left(a_{13} \mid W\right)=(2,2,0) \\
& r\left(a_{1} \mid W\right)=(1,1,1)
\end{aligned}
$$

Terlihat $r(v \mid W)$ untuk setiap simpul $v \in$ $\mathrm{C}_{1,3}$ berbeda. Maka $\mathrm{W}_{1}$ dan $\mathrm{W}_{2}$ merupakan resolving set

\section{Graf $\mathrm{C}_{3,3}$}

$$
\begin{gathered}
W=\left\{a_{11}, a_{12}, a_{21}, a_{22}, a_{31}, a_{32}\right\} \\
r\left(a_{11} \mid W\right)=(0,2,3,3,4,4) \\
r\left(a_{12} \mid W\right)=(2,0,3,3,4,4) \\
r\left(a_{13} \mid W\right)=(2,2,3,3,4,4) \\
r\left(a_{21} \mid W\right)=(3,3,0,2,3,3) \\
r\left(a_{22} \mid W\right)=(3,3,2,0,3,3) \\
r\left(a_{23} \mid W\right)=(3,3,2,2,3,3) \\
r\left(a_{31} \mid W\right)=(4,4,3,3,2,2) \\
r\left(a_{32} \mid W\right)=(4,4,3,3,2,0) \\
r\left(a_{33} \mid W\right)=(4,4,3,3,2,2) \\
r\left(a_{1} \mid W\right)=(1,1,2,2,3,3)
\end{gathered}
$$




$$
\begin{aligned}
& r\left(a_{2} \mid W\right)=(2,2,1,1,2,2) \\
& \quad r\left(a_{3} \mid W\right)=(3,3,2,2,1,1)
\end{aligned}
$$

Terlihat $r(v \mid W)$ untuk setiap simpul $v \in$ $\mathrm{C}_{3,2}$ berbeda. Maka W merupakan resolving set.

Dari pengkonstruksian himpunan pembeda diatas didapatkan bahwa setiap m simpul backbone dengan sedikitnya $n-1$ simpul anting pasti merupakan himpunan pembeda.

Dengan adanya pernyataan tersebut maka graf $\mathrm{C}_{\mathrm{m}, \mathrm{n}}$ memiliki batas bawah yaitu dim $\left(C_{m, n}\right) \geq m(n-1)$.

ii. Misal himpunan pembeda $\mathrm{W}=$ $\left\{\begin{array}{r}a_{11}, a_{12}, a_{13}, \ldots, a_{1 n-1}, a_{21}, a_{22}, a_{23} \\ \ldots, a_{2 n-1}, \ldots \ldots \ldots \ldots a_{m n-1}\end{array}\right.$
dan diperoleh representasi
sebagai berikut:

- Representasi untuk anting graf $C_{m, n}$

$$
\begin{gathered}
r\left(a_{12} \mid W\right)=(2,2) \\
r\left(a_{13} \mid W\right)=(2,2,3,3) \\
r\left(a_{14} \mid W\right)=(2,2,2) \\
\cdot \\
=(2,2,2, \ldots \ldots, 3,3,3, \ldots \ldots) \\
r\left(a_{22} \mid W\right)=(3,3) \\
r\left(a_{23} \mid W\right)=(3,3,2,2) \\
r\left(a_{24} \mid W\right)=(3,3,3) \\
\cdot \\
\cdot \\
\cdot \\
r\left(a_{2 n} \mid W\right) \\
=(3,3,3, \ldots \ldots, 2,2,2, \ldots \ldots .)
\end{gathered}
$$$$
r\left(a_{m n} \mid W\right)
$$$$
=(\ldots \ldots, 2,2,2, \ldots \ldots 3,3,3 .)
$$

- Representasi untuk simpul backbone

$$
\begin{gathered}
r\left(a_{1} \mid W\right)=(1,1,1, \ldots \ldots, 2,2,2, \ldots \ldots) \\
r\left(a_{2} \mid W\right)=(2,2,2, \ldots \ldots, 1,1,1, \ldots \ldots) \\
\cdot \\
\cdot \\
r\left(a_{m} \mid W\right)=(\ldots \ldots \ldots, 1,1,1, \ldots 2,2,2)
\end{gathered}
$$

Dari hasil representasi diatas tidak ada representasi yag sama maka dim dari graf ulat adalah $\mathrm{m}(\mathrm{n}-1)$ dengan begitu diperoleh , batas atas yaitu $\left(\mathrm{C}_{\mathrm{m}, \mathrm{n}}\right) \leq m(n-1)$.

a.Menentukan diameter dari graf ulat Untuk menentukan diameter dari graf ulat terlebih dahulu kita harus mengkonstruksi graf tersebut. Hasil dari pengkonstruksian sebagai berikut

$$
\begin{aligned}
& C_{1, n}=2 \\
& C_{2, n}=3
\end{aligned}
$$

$$
C_{3, n}=4
$$

.

$$
C_{m, n}=m+1
$$

Teorema 1.1

Graf ulat $\left(C_{m, n}\right)$ dengan $m \geq 1, n \geq 2$ memiliki diameter $m+1$ dan dimensi metrik $m(n-1)$.

Yang pertama akan dibuktikan diameter dari Graf ulat $\left(C_{m, n}\right)$ dengan $m \geq$ $1, n \geq 2$ adalah $m+1$. 
Akan dibuktikan bahwa ada dua titik yang memiliki jarak $m+1$.

Bukti:

Untuk membuktikan hal ini, tanpa mengurangi keumuman graf ulat dapat digambarkan sebagai berikut:

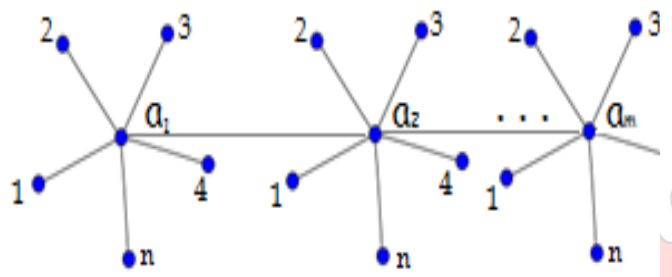

Gambar 4. Graf Ulat m,n

Setiap dua simpul backbone hanya dapat dihubungkan melalui sisi yang menghubungkan simpul-simpul backbone tersebut. Sedangkan subgraf dari graf ulat yang terdiri dari simpul backbone membentuk suatu lintasan yaitu

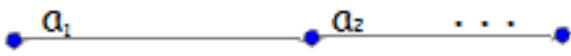

Gambar 5. Graf Lintasan

Kita ketahui bahwa suatu lintasan $\mathrm{P}_{\mathrm{m}}$ memiliki diameter dari lintasan adalah m-1, sehingga jarak $a_{1}$ dan $a_{m}$ adalah m-1. Kemudian ambil sebarang anting dari $a_{1}$ dan $a_{m}$ misal $a_{1 s}$ dan $a_{m s}$. Dari sifat graf ulat yaitu $a_{1 s}$ hanya terhubung pada simpul backbone $a_{1}$ dan $a_{m s}$ hanya terhubung pada simpul backbone $a_{m}$ sehingga

$$
\begin{aligned}
& d\left(a_{1 s}, a_{m s}\right)=d\left(a_{1 s}, a_{1}\right)+ \\
& \begin{array}{c}
d\left(a_{1}, a_{m}\right)+d\left(a_{m}, a_{m s}\right) \\
=1+\mathrm{m}-1+1
\end{array}
\end{aligned}
$$

$$
=\mathrm{m}+1
$$

Terbukti bahwa diameter dari Graf ulat $\left(C_{m, n}\right)$ dengan $m \geq 1, n \geq 2$ adalah $m+$ 1.

$>$ Yang kedua akan dibuktikan dimensi metrik dari Graf ulat $\left(C_{m, n}\right)$ dengan $m \geq 1, n \geq 2$ adalah $m(n-1)$.

Bukti:

Pada point i diperoleh graf $\mathrm{C}_{\mathrm{m}, \mathrm{n}}$ memiliki batas bawah yaitu dim $\left(\mathrm{C}_{\mathrm{m}, \mathrm{n}}\right) \geq m(n-1)$ dan pada point ii diperoleh graf $\mathrm{C}_{\mathrm{m}, \mathrm{n}}$ memiliki batas atas yaitu $\operatorname{dim}\left(\mathrm{C}_{\mathrm{m}, \mathrm{n}}\right) \leq$ $m(n-1)$ maka dapat disimpulkan bahwa graf $\mathrm{C}_{\mathrm{m}, \mathrm{n}}$ memiliki dim $\left(\mathrm{C}_{\mathrm{m}, \mathrm{n}}\right)=m(n-1)$

\section{PENUTUP}

\section{Simpulan}

a. Graf ulat $\left(C_{m, n}\right)$ dengan $m \geq 1, n \geq 2$ memiliki diameter $m+1$ dan dimensi metrik $m(n-1)$.

\section{Saran}

Dalam penelitian ini, ada beberapa saran penulis terkait penelitian ini, diantaranya:

Bisa dijadikan acuan untuk meneliti dengan graf yang lain

\section{DAFTAR PUSTAKA}

Gumilar Dony,dkk. Dimensi Metrik Graph Lopster $L_{n}$. E-Jurnal Matematika Vol. 2, No.2, Mei 2013, 42-48 ${ }^{[1]}$

Melati,R.A .2011.Resolving set dan Dimensi Metrik graf lengkap, Graf lintasan dan 
Restu Ria Wantika : Dimensi Metrik dan diameter graf Ulat $\mathrm{C}_{\mathrm{m}, \mathrm{n}}$

Graf bipartit lengkap. Universitas Andalas. ${ }^{[2]}$

Rosyida E.M. 2009.Nilai Maksimum dan Minimum Pelabelan- $\gamma$ pada Graf Pohon Pisang Bn,k dan Graph Persahabatan $D_{m}{ }^{3}$.Universitas Sebelas Maret Surakarta. ${ }^{[3]}$

Asih,J.A. 2009. Pelabelan Harmonious pada Graf Firecracker, Graf Hair Cycle dan Graf Korona. Universitas Indonesia. ${ }^{[4]}$

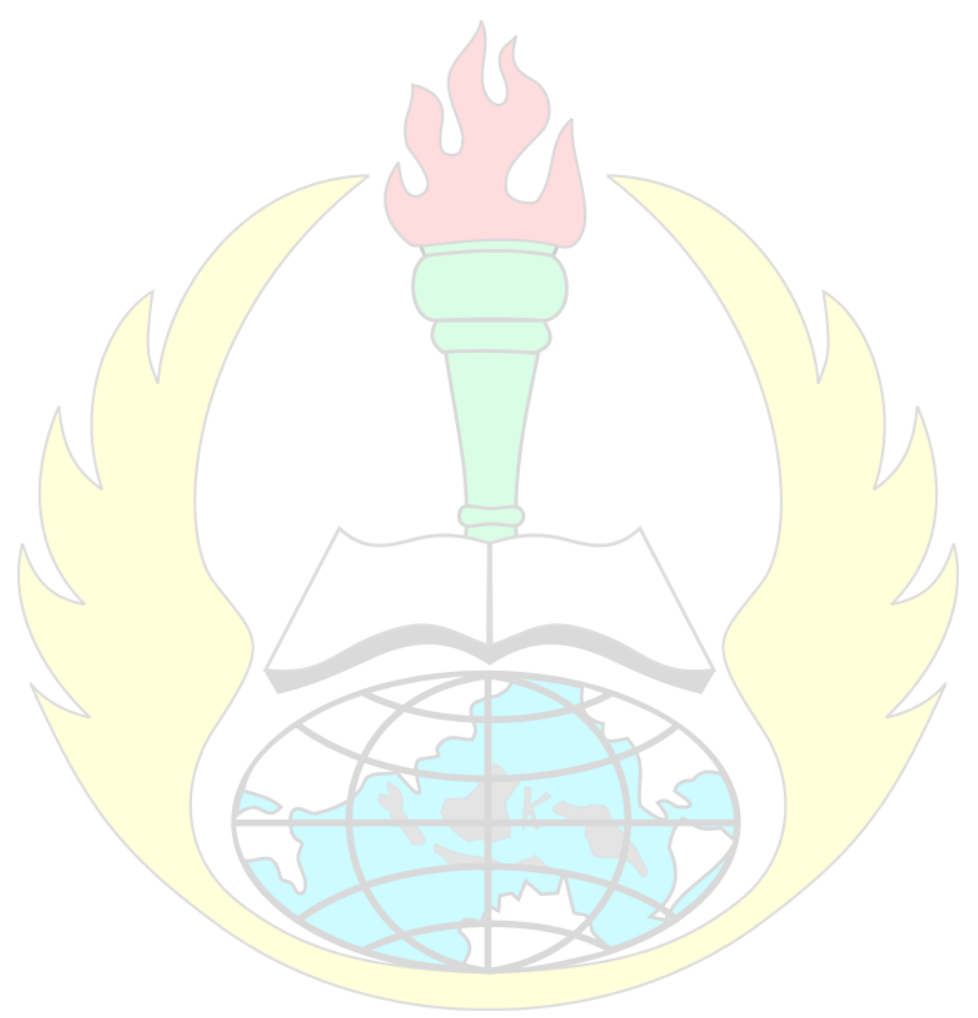

